Tropical Journal of Pharmaceutical Research, June 2005; 4 (1): 363-368

(C) Pharmacotherapy Group,

Faculty of Pharmacy, University of Benin,

Benin City, Nigeria

All rights reserved.

Research Article

Available online at http://www.tjpr.freehosting.net

\title{
Packing and cohesive properties of some locally extracted starches
}

\author{
OA. Itiola* and OA. Odeku
}

Department of Pharmaceutics and Industrial Pharmacy, Faculty of Pharmacy, University of Ibadan, Ibadan, Nigeria

\begin{abstract}
Purpose: The packing and cohesive properties of locally developed cassava, potato and yam starches have been characterised using the maximum volume reduction due to packing as expressed by the Kawakita constant a, and the angle of internal flow, $\theta$, respectively.

Methodology: The starches were characterized for their particle size, shape and particle size distribution using optical microscopy. Tapping experiments were used to quantify the packing and cohesive properties of the starches. The volume reduction ability was estimated using the Kawakita equation.

Results: The shape factor of the starches provided a proportionality constant between the particle size and surface area. The rank order of the particle size and shape factor of the starches was yam>potato>cassava. The ranking of maximum volume reduction, $a$, for the starches was potato > cassava > yam while the ranking for the angle of internal flow, $\theta$, an index of cohesiveness, was cassava $>$ potato $>$ yam. The values of these parameters depended on the physical properties of the starches.

Conclusion: The results obtained indicate that the physical properties of the particles affect the packing and cohesive properties of the starches, and are important in predicting the behaviour of the starches during handling and use in pharmaceutical preparations. These properties need to be closely controlled in pre-formulation studies.
\end{abstract}

Key words: Packing and cohesive properties, starch, cassava, potato, yam.

*Corresponding Author, E. mail: oprofit@yahoo.com Tel. 2348022912227 


\section{INTRODUCTION}

In a previous investigation, Itiola (1) studied the compressional characteristics of starches obtained locally from cassava, potato and yam tubers. The starches were found to deform mainly by plastic flow in a similar manner to many official and proprietary starches. The mechanical properties of tablets produced from the starches also provided some insight into their probable effects on the mechanical properties of pharmaceutical tablets.

However, in addition to their uses as disintegrants and binders in tablet formulations, the starches can also be employed as fillers and glidants in powder, tablet and capsule formulations. Thus, in addition to the properties already investigated, the packing and cohesive properties of the starches require characterisation. These properties influence various aspects of powder processing including their milling, blending and storage, their flow from hoppers, their compression to produce granules or tablets, and their packing into powder containers or capsule shells.

The packing and cohesive properties of the starches depend to a large extent on the particle size distribution and shape. The shape of a particle is a very difficult variable to describe and is commonly expressed by a scalar quantity known as shape factor (shape coefficient) which serves as a proportionality constant between mean particle diameter and particle surface area and volume (2). Shape factor can also serve to relate results of experimental particle size measurements by different methods.

Simple tapping experiments can also be used to quantify the packing and cohesive properties of the starches $(3,4)$. The volume reduction ability of the starches during packing can be estimated using the Kawakita function which relates the degree of volume reduction to the applied pressure $(5,6)$. The function has been used in connection with compaction under high loads $(6,7,8)$, but it can also be used in the following form to study the volume reduction of a powder due to tapping $(4,5)$ :

$$
\mathrm{N} / \mathrm{C}=1 / \mathrm{a} \cdot \mathrm{N}+1 / \mathrm{ab}
$$

$$
\begin{aligned}
& \mathrm{C}=\left(\mathrm{V}_{0}-\mathrm{V}_{\mathrm{N}}\right) / \mathrm{V}_{\mathrm{O}} \\
& \begin{array}{l}
\text { and } \\
\mathrm{a}=\left(\mathrm{V}_{0}-\mathrm{V}_{\infty}\right) / \mathrm{V}_{0}
\end{array}
\end{aligned}
$$

where $a$ and $b$ are constants characterising the material, $\mathrm{N}$ is the number of taps, $\mathrm{C}$ represents the degree of volume reduction achieved after $\mathrm{N}$ taps, $V_{0}$ is the maximum bulk volume of the powder, $V_{N}$ is the bulk volume of the powder after $\mathrm{N}$ taps, and $\mathrm{V}_{\infty}$ is the minimum bulk volume. The constant a has practical application for powders since it describes the maximal possible relative decrease in the initial bulk volume due to tapping.

While Equation 3 can be used to determine $a$, it has been shown that it can be difficult to determine $\mathrm{V}_{\infty}$ from tapping procedures (4). However, a can be determined with reasonable accuracy from the slope of the linear plot of $\mathrm{N} / \mathrm{C}$ versus $\mathrm{N}$ in Equation 1 since the slope of the function will not change. Thus, the determination of $a$ in this case does not depend on reaching $\mathrm{V}_{\infty}$.

Another parameter which can be determined using simple tapping experiments is the angle of internal flow $(\theta)$ which is a direct measure of the cohesiveness of powders. It can be obtained from plots using the decreasing porosity (E) of a material with increasing number of taps, N. Varthalis and Pilpel (3) found the linear relationship between $E$ and $N$ to be of the form:

$$
E^{2} N / 1-E=G N+K_{0}
$$

where $\mathrm{G}$ and $\mathrm{K}_{\mathrm{o}}$ are constants for each material. The constant $\mathrm{K}_{\circ}$ has practical application for powders because it describes the material before any tappings. Since the cohesiveness of a powder is a measure of the difficulty with which the particles can flow past each other when tapped or compressed, $\mathrm{K}_{\mathrm{o}}$ can be employed to determine the angle of internal flow of the material after tapping (3). Full details of the method are given under the sections on Materials and Methods, and Results and Discussion. 
The objective of the present work has been to characterise the packing and cohesive properties of the three local starches: cassava, potato and yam starches, using the maximum volume reduction due to packing (a), and the angle of internal flow $(\theta)$, respectively.

\section{MATERIALS AND METHODS Materials}

The starches used were: Cassava starch - prepared from the tubers of cassava plant, Manihot utilissima; Potato starch prepared from the tubers of potato plant, Ipomea batatas and yam starch - prepared from the tubers of yam plant, Dioscorea rotundata. The starches were extracted from the relevant tubers using established procedures $(9,10)$.

\section{Characterisation of the starches}

The particle size distribution and shape of the starch grains were determined by optical microscopy on approximately 300 particles for each starch, from which the values of the mean projected particle diameter (đ) were calculated (9). Particle densities were determined by the pycnometer method with xylene as the displacement fluid (11).

The shape factor (shape coefficient), $\alpha$, of the particles of each starch was calculated from the expression (12):

$\alpha=\operatorname{Sw} \rho_{\mathrm{s}}$ de $+\mathrm{R}$

where $S w$ is the specific surface area of the particles $\left(\mathrm{m}^{2} . \mathrm{g}^{-1}\right)$ which was determined from the size distribution of the particles (13); de is the Heywood equivalent diameter $(\mu \mathrm{m})$ and is expressed as:

de $=\frac{(4 \times 0.77 \times L \times B)^{1 / 2}}{(\pi)}$

Here, $R$, the elongation ratio is $L / B$ where $L$ and $B$ are the arithmetic mean values of the particle length and breadth respectively; $\rho_{\mathrm{s}}$ is the particle density $\left(\mathrm{g} . \mathrm{cm}^{-3}\right)$ of each starch.

\section{Determination of volume and density parameters}

The initial bulk volume, $V_{o}$, of $20 \mathrm{~g}$ of each of the starches was determined in a glass cylinder. The starches were then subjected to various number of taps in the cylinder according to British Standard 1460 (38 taps per minute). Values of bulk volume $\left(V_{N}\right)$ for the starches were determined at intervals of 25 taps, and values of bulk density were calculated using the weight of the starches. The packing fraction $\left(P_{f}\right)$ values for the starches were then obtained from the ratios of the bulk density to the particle density. Determinations were made in quadruplicate.

\section{RESULTS AND DISCUSSION}

Figure 1 shows photomicrographs of the starches. None of the starches were truly spherical with their shape being round to ovoid. Cassava starch showed the most distinct round shape while yam starch showed an ovoid shape.

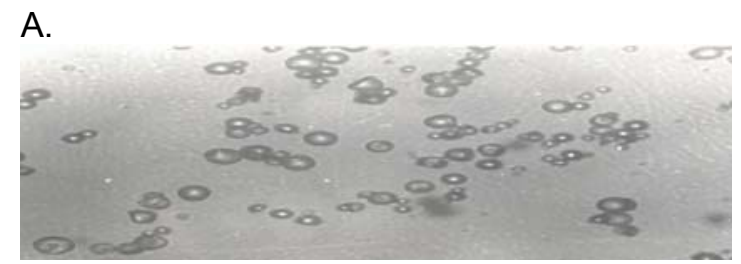

B
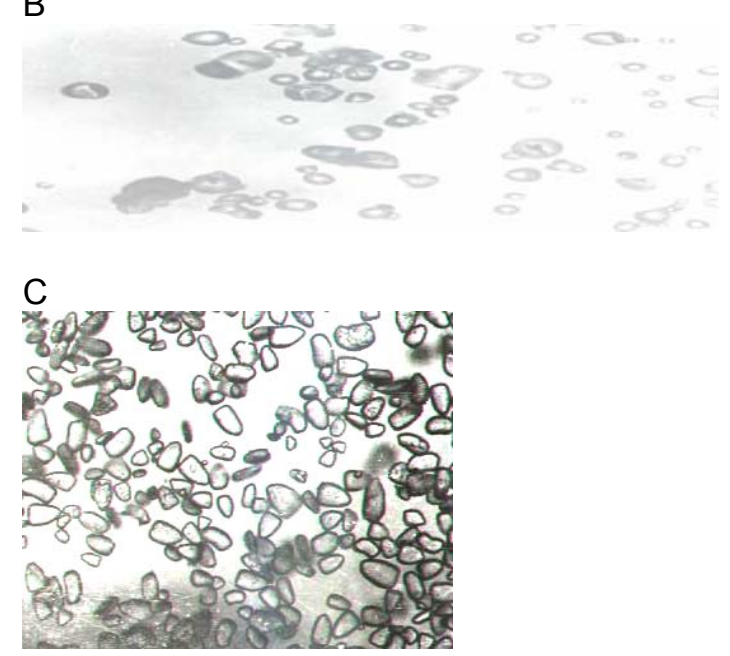

Fig. I Photomicrograph of the starches (Mag. X 25). A. cassava; B, potato; C, yam. 
The physical and geometric properties of the particles are presented in Table 1. The rank order of the particle size, Heywood diameter and the shape factor (shape coefficient) of the starches was yam>potato>cassava. The shape factor has been shown to serve as a proportionality constant between particle size and surface area (2). This relationship applies to the starches. Thus, cassava starch which is round and more regular in shape has the lowest shape factor. But, as the shape becomes more angular as in yam starch which is ovoid, the shape factor increased (14).

Plots of N/C versus number of taps, $N$, exhibited the largest maximum volume reduction due to packing while yam starch exhibited the lowest. The process of volume reduction of powders is dependent on particle properties such as shape, size and the degree of interparticulate friction (4). However, it should be appreciated that it is not readily possible to quantify the relative contributions of each of these parameters to the volume reduction ability of the starches. There exists no general rules about the influence of particle size and shape on packing and cohesive properties of powders and both parameters appear to interact $(4,15)$ Thus, it would appear that under the applied tapping

Table 1: Physical and geometric properties of the various starches.

\begin{tabular}{|c|c|c|c|c|c|c|c|}
\hline Starch & $\begin{array}{c}\text { Geometric } \\
\text { Shape }\end{array}$ & $\begin{array}{c}₫ \\
(\mu \mathrm{m})\end{array}$ & $\begin{array}{c}\rho \\
\left(\mathrm{g} . \mathrm{cm}^{-3}\right)\end{array}$ & de & $\mathrm{N}$ & $\begin{array}{c}S_{w} \\
\left(m^{2} g^{-1}\right)\end{array}$ & $\propto$ \\
\hline Cassava & Round & 9.2 & 1.479 & 3.66 & 1.00 & 0.035 & 1.19 \\
\hline Potato & Round & 12 & 1.481 & 6.93 & 1.00 & 0.036 & 1.37 \\
\hline Yam & Ovoid & 18 & 1.475 & 11.56 & 1.48 & 0.049 & 2.32 \\
\hline
\end{tabular}

Table 2. Values of maximum volume reduction due to packing (a) and angle of internal flow $(\theta)$ for the starches

\begin{tabular}{lcc}
\hline Nature of starches & $\begin{array}{c}\text { Maximum volume Reduction, a } \\
(\%)\end{array}$ & $\begin{array}{c}\text { Angle of internal flow, } \theta \\
\text { (Degrees) }\end{array}$ \\
\hline Cassava & 41.3 & 20.65 \\
Potato & 55.0 & 17.68 \\
Yam & 38.0 & 8.48 \\
\hline
\end{tabular}

for the starches gave the linear relationship shown in Fig. 2 with correlation coefficient, $r>$ 0.980 (significant at $p<0.05$ ). Values of $a$ for the starches were obtained from the slopes of the straight lines and are presented as percentages in Table 2. The ranking of $a$, the maximum volume reduction for the starches, was potato > cassava $>$ yam. This indicates that potato starch pressure which would overcome to a large extent the electrostatic forces of attraction between the particles of the starches (1), the round shape and smaller particle size of potato and cassava starches promoted closer packing of particles than the ovoid shape and larger particle size of yam starch. 


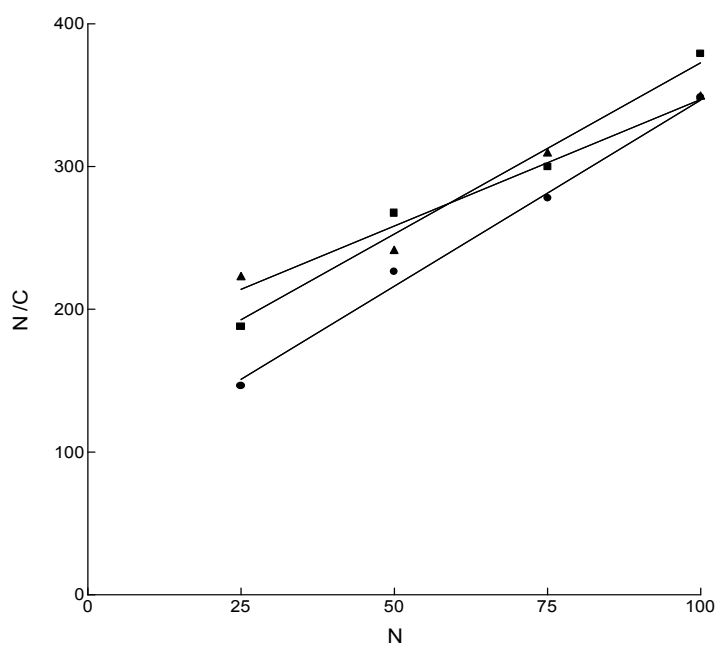

Fig. 2 Plots of $\mathrm{N} / \mathrm{C}$ versus number of taps, $\mathrm{N}$, for the starches. $\boldsymbol{~}$, cassava; $\boldsymbol{\Lambda}$, potato; $\bullet$, yam.

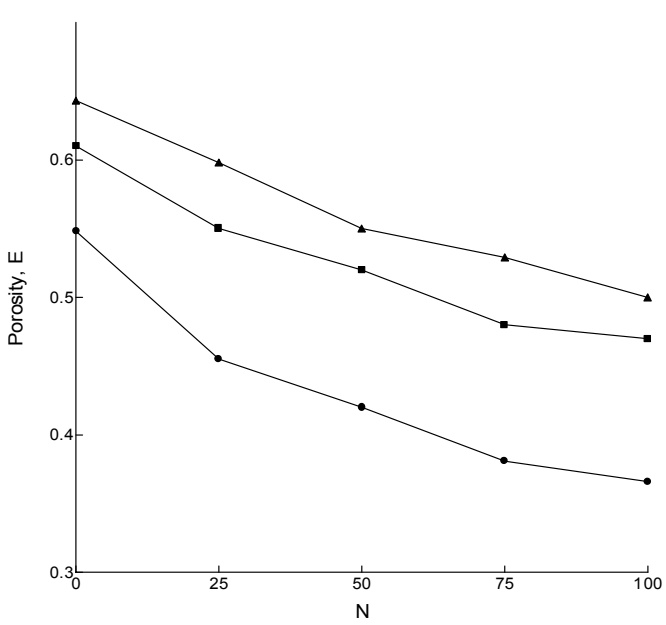

Fig. 3 Plots of porosity, E, versus number of taps, $\mathrm{N}$, for the starches. $\square$, cassava; $\boldsymbol{\Lambda}$, potato; $\bullet$, yam.

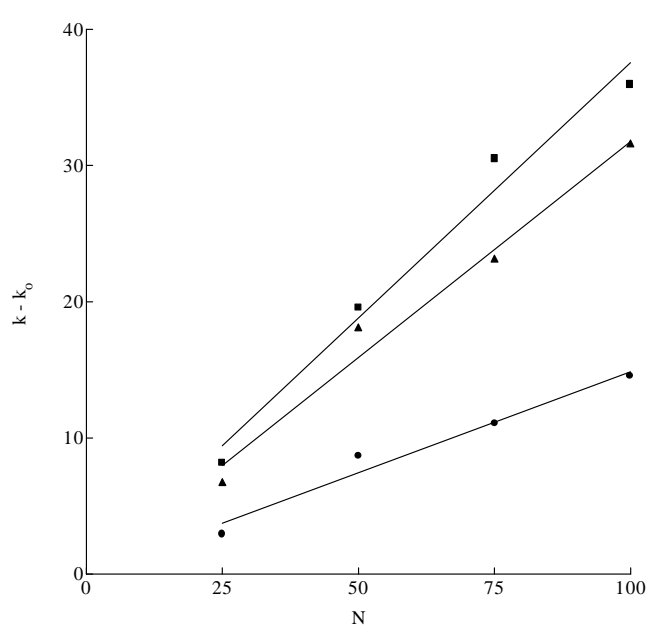

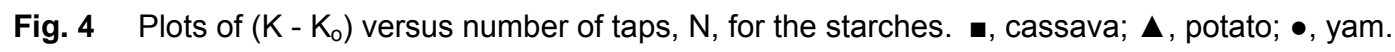

Information on the volume reduction ability of materials is invaluable, especially in the production of solid dosage forms. For example, in capsule filling, it is usually desirable to be able to fill powders or granules into capsules of a smaller size, even if the required fill weight of the material is large (3). The information is also important in the production of powdered products such as drug powders, baby food, detergents and cement, which are packed into suitable containers. The space occupied by such products can be greatly reduced with the application of the volume reduction ability of the materials, especially in the consideration of transportation and storage.

Fig. 3 shows how the porosity, $E=(1$ $P_{f}$ ), of the starches varied with the number of taps applied. It can be observed for all the starches that there was a relationship between the porosity, $\mathrm{E}$ and the number of taps, $\mathrm{N}$. Plotting $E^{2} N /(1-E),(=K)$ against $N(3)$ gave a series of straight lines $(r>0.984$; significant at $p$ $<0.05)$, whose intercepts on the ordinate were defined as $\mathrm{K}_{\mathrm{o}}(3)$. Then plotting $\left(\mathrm{K}-\mathrm{K}_{\mathrm{o}}\right)$ against $\mathrm{N}$ gave the linear relationship shown in Fig. $4(r$ $>0.985$; significant at $p<0.05$ ). 
The slopes of the lines in Fig. 4 were equal to $\tan \theta$, where $\theta$ is the angle of internal flow. Values of $\theta$ for the starches are included in Table 2. The ranking of $\theta$ was cassava $>$ potato $>$ yam. The ranking for $\theta$ exhibits an inverse correlation with the values of mean particle diameter (đ) and the shape factor of the starches (see Table 2). It has been shown that cohesiveness is usually inversely related to the particle diameter of materials (15). In general, the smaller the particle size and shape factor, the more cohesive the particles.

The angle of internal flow is of importance in the consideration of the flow of powdered or granulated materials. For example, the angle is of particular relevance in the consideration of the flow of materials from hoppers through the feed frame into tabletting machines to obtain uniform flow and minimize weight variation of tablets (3). A similar consideration applies in the flow of materials through feed frames into capsule shells.

\section{CONCLUSION}

The characterization of the starches in the present work provides some insight into their packing and cohesive properties. The results show that potato starch would be the most useful of the three starches when extensive packing of material is required. On the other hand, yam starch with the lowest cohesiveness should be the starch of choice when good flow ability is the requisite property. These findings should be useful in the handling and industrial processing of the starches, and in their application for the production of powders, tablets, capsules, and other relevant drug delivery systems.

\section{REFERENCES}

1. Itiola, O. A. Compressional characteristics of three starches and the mechanical properties of their tablets. Pharm. World J. 1991; 8 (3) : 91 - 94.

2. Rippie, E. G. Mixing. In: theory and Practice of Industrial Pharmacy. Lachman, L. Lieberman, H. A. and Kanig, J. L. (Eds) $3^{\text {rd }}$ Edition Lea \& Febiger., Philadelphia. 1986, Pp. 13-20.

3. Varthalis, S. and Pilpel, N. Anomalies in some properties of powder mixtures. J. Pharm. Pharmacol. 1976; 28 : 415 - 419.

4. Podczeck, F., Sharma, M. The influence of particle size and shape of components of binary powder mixtures on the maximum volume reduction due to packing. Int. J. Pharm. 1996; $137: 41$ - 47.

5. Ludde, K. H., Kawakita, K. Die pulverkompression. Pharmazie1966; $21: 393$ - 403.

6. Kawakita, K. and Ludde, K. H. Some considerations on powder compression equations. Powder Technol. 1970/71; $4: 61$ - 68.

7. Lin, C., Cham, T. Compression behaviour and tensile strength of heat-treated polyethylene glycols. Int. J. Pharm. 1995; 118 : 169 - 179.

8. Odeku, O. A., Itiola, O. A. Evaluation of khaya gum as a binder in a paracetamol tablet formulation. Pharm. Pharmacol. Commun. 1998; 4 : 183-188.

9. Radley, J. Starch production technology. ASP Ltd, London, 1976. pp. $189-211$.

10. Dare, K, Akin-Ajani, D. O., Odeku, O. A. Itiola, O. A., Odusote, O. M. Effects of pigeon pea and plantain starches on compressional, mechanical and disintegration properties of paracetamol tablets. Drug Dev. Ind. Pharm. 2006; 32: 357 - 365.

11. Odeku, O. A. Awe, O. O. Popoola, B., Odeniyi, M. A., Itiola, O. A. Compression and mechanical properties of tablet formulations containing corn, sweet potato, and cocoyam starches as binders. Pharm. Tech. 2005; 29 (4): 82-90.

12. Nikolakakis, I., Pilpel, N. Effects of particle size and particle shape on the tensile strength of powders. Powder Technol. 1985; 45: 79-82.

13. Stanley-wood, N. G., Shubair, M. S. The influence of binder concentration on the bond formation of pharmaceutical granules. J. Pharm. Pharmacol. 1979; 31: 429-433.

14. Paronen, P., Juslin, M. Compressional characteristics of four starches. J. Pharm. Pharmacol., 1983; 35: 627-635.

15. Shotton, E., Obiorah, B. A. the effect of particle shape and crystal habit on properties of sodium chloride. J. Pharm. Pharmacol. 1973; 25: Suppl. 37P - 43P.

16. Pilpel, N. The cohesiveness and tensile strength of powders. Manufac. Chem. Aero. News. 1969; 40 (2): $29-31$. 